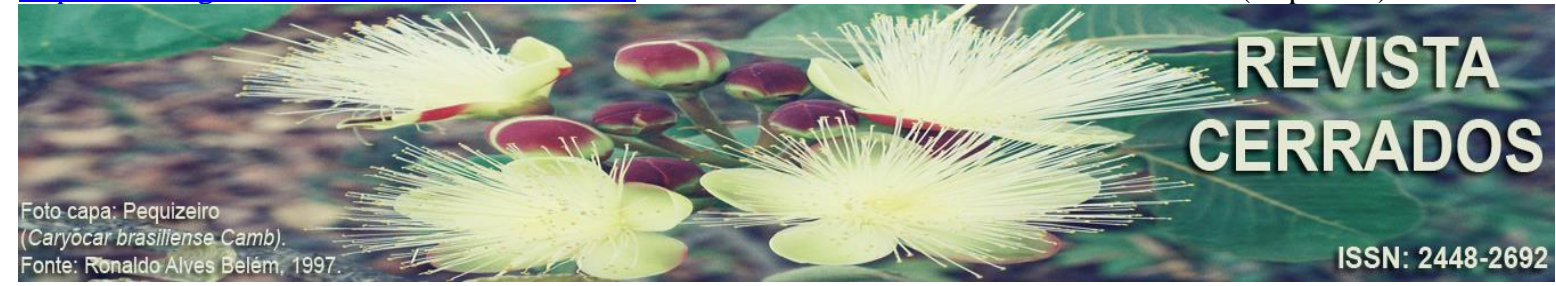

\title{
OPORTUNIDADES E DESAFIOS DA CRIAÇÃO DE UNIDADES DE CONSERVAÇÃO: reflexões sobre as experiências no Estado de Goiás, Brasil
}

\section{OPPORTUNITIES AND CHALLENGES OF CREATING PROTECTED AREAS: reflections on experiences in the state of Goiás, Brazil}

\section{OPORTUNIDADES Y RETOS DE CREAR UNIDADES DE CONSERVACIÓN: reflexiones sobre experiencias en el estado de Goiás, Brasil}

\author{
Ana Cristina Araújo Foli \\ Universidade Federal de Goiás - UFG, Goiânia, Goiás, Brasil \\ E-mail: 〈anacafoli@outlook.com> \\ Karla Maria Silva de Faria \\ Universidade Federal de Goiás - UFG, Goiânia, Goiás, Brasil \\ E-mail: <karla_faria@ufg.br>
}

\begin{abstract}
RESUMO
Este trabalho apresenta uma abordagem qualitativa sobre as oportunidades e desafios da criação de Unidades de Conservação no Brasil e especificamente no Estado de Goiás. O estudo foi segmentado em duas etapas, sendo a primeira baseada em pesquisas bibliográficas e acervos governamentais, orientadas pelos seguintes questionamentos: Quem são as áreas protegidas no Brasil e no mundo? O que o Brasil ganha com a criação de áreas protegidas? O país atende aos principais convênios e conferências internacionais sobre a regulação de áreas protegidas? Na segunda etapa foi realizado um levantamento sobre os dados das unidades de conservação em agências e órgãos públicos estaduais e federais do estado de Goiás, além da utilização de imagens de geoprocessamento referentes ao ano de 2019, disponibilizadas pelo site Map Biomas. As análises apontaram que, em Goiás, muitas dessas áreas existem apenas no papel, pois não apresentam conselho gestor ou plano de manejo, sem que, na prática, qualquer ação de preservação ou conservação seja efetivada. Dessa forma, verifica-se a necessidade de maior gerenciamento das áreas protegidas em Goiás.
\end{abstract}

Palavras-chave: Unidades de Conservação. Oportunidades e Desafios. Goiás. Brasil. 
FOLI, A. C. A.; FARIA, K. M. S. de.

Oportunidades e Desafios da Criação de Unidades de Conservação: reflexões sobre as experiências no Estado de Goiás, Brasil.

\begin{abstract}
This work presents a qualitative approach on the opportunities and challenges of creating protecded areas in Brazil and specifically in the state of Goiás. The study was divided into two stages, the first based on bibliographic research and government collections, being guided by the questions: Who are the protected areas in Brazil and in the world? What Brazil gains from the creation of protected areas? The country meets the main international agreements and conferences on the regulation of protected areas? In the second stage, a survey was carried out on the data of protected areas in state and federal agencies and public bodies in the state of Goiás, in addition to the use of geoprocessing images for the year 2019 provided by the Map Biomas website. The analyzes showed that, in Goiás, many of these areas exist only on paper, as they do not have a managing council or management plan, without, in practice, any preservation or conservation action being carried out. Thus, there is a need for greater management of protected areas in Goiás.
\end{abstract}

Keywords: Protected Areas. Opportunities and Challenges. Goiás. Brazil.

\title{
RESUMEN
}

Este trabajo presenta un enfoque cualitativo sobre las oportunidades y retos de la creación de Unidades de Conservación en Brasil y específicamente en el estado de Goiás. El estudio si dividió en dos pasos, el primero basado en la investigación bibliográfica y las colecciones gubernamentales, guiada por las siguientes preguntas: ¿Quiénes son las áreas protegidas en Brasil y en el mundo? ¿Qué gana Brasil con la creación de áreas protegidas? ¿Cumple el país con los principales convenios y conferencias internacionales sobre regulación de áreas protegidas? En la segunda etapa, se realizo un relevamiento de los datos de las unidades de conservación en dependencias estatales, federales y organismos públicos del estado de Goiás, además del uso de imágenes de geoprocesamiento para el año 2019, hecho disponible por el sitio web Map Biomas. Los análisis mostraron que, en Goiás, muchas de estas áreas existen solo en papel, ya que no tienen um consejo de administración ni un plan de gestión, sin que, en la práctica, se lleve a cabo ninguna acción de preservación o conservación. Por lo tanto, existe la necesidad de una mayor gestión de las áreas protegidas en Goiás.

Palabras-clave: Unidades de Conservación. Oportunidades y Retos. Goiás. Brasil.

\section{INTRODUÇÃO}

A perda da biodiversidade e a consequente fragmentação de ambientes tem se mostrado um dos grandes desafios ambientais da atualidade. Embora exista algum consenso no sentido de que a preservação da natureza implica em benefícios os mais diversos para o ser humano, esse debate está longe de ser esgotado.

O contexto de criação de áreas protegidas, iniciado em meados do século XIX, está relacionado aos aspectos preservacionistas da natureza, com ênfase na ausência da 
FOLI, A. C. A.; FARIA, K. M. S. de.

Oportunidades e Desafios da Criação de Unidades de Conservação: reflexões sobre as experiências no Estado de Goiás, Brasil.

interferência humana. Diversos autores (BARROS, 2004; PEREIRA, 2005; MEDEIROS, 2003, 2006) apontam que a criação de áreas protegidas no mundo tem sido a principal resposta aos desafios ambientais na atualidade. Todavia, para transformar áreas naturais em unidades de conservação é necessário ter argumentos baseados em critérios científicos, ecológicos e operacionais (WWF BRASIL, 2020).

De acordo com a União Mundial para a Conservação da Natureza (também conhecida pelas siglas UICN ou IUCN), as áreas protegidas podem ser definidas como "um espaço geográfico claramente definido, reconhecido, com objetivo específico e gerido por meios eficazes, sejam jurídicos ou de outra natureza, para alcançar a conservação da natureza no longo prazo, com serviços ecossistêmicos e valores culturais associados" (UICN, 2017, p. $5)$.

Nesse sentido, a criação dessas áreas constitui-se importante estratégia de controle do território, pois estabelecem dinâmicas e limites de uso e ocupação específicos (MEDEIROS, 2006). O Brasil possui a maior área protegida em hectares no sistema mundial, cerca de 2.552.197 $\mathrm{km}^{2}$ (Ministério do Meio Ambiente, 2020). O país é reconhecido internacionalmente devido suas características continentais e o grau de importância de sua biodiversidade, e por buscar um equilíbrio entre o desenvolvimento econômico e social e seu grande patrimônio natural.

Entretanto, como aponta a UICN (2019, p. 1) deve-se também "reconhecer que as áreas protegidas, os territórios indígenas e as comunidades locais são a última fronteira de proteção da biodiversidade mais importante do planeta e a base para o desenvolvimento social e econômico sustentável". Sendo assim, faz-se necessário apontar o que representam as áreas protegidas neste início de século XXI.

Nesse sentido, este artigo tem por objetivo compreender quais as oportunidades e os desafios enfrentados no Brasil e detalhadamente no Estado de Goiás no âmbito da criação de Unidades de Conservação.

\section{MATERIAL E MÉTODOS}

O presente estudo apresenta abordagem qualitativa segmentada em duas etapas. A primeira baseou-se em pesquisas bibliográficas, orientadas principalmente a partir dos 
FOLI, A. C. A.; FARIA, K. M. S. de.

Oportunidades e Desafios da Criação de Unidades de Conservação: reflexões sobre as experiências no Estado de Goiás, Brasil.

seguintes questionamentos: quem são as áreas protegidas no Brasil e no mundo? O que o Brasil ganha com a criação de áreas protegidas? O país atende aos principais convênios e conferências internacionais sobre a regulação de áreas protegidas?

Demais pesquisas foram realizadas por meio de acervos governamentais, como o Ministério do Meio Ambiente (MMA) e o Instituto Chico Mendes de Conservação da Biodiversidade (ICMBio), além de embasamento na legislação vigente, especialmente a Lei Federal $n^{\circ} 9.985 / 2000$ e a Lei Estadual n $14.247 / 2002$.

Na segunda etapa buscou-se compreender as oportunidades e desafios da criação de Unidades de Conservação, com ênfase no Estado de Goiás. Para tanto, foi realizado um levantamento sobre os dados das unidades de conservação em agências e órgãos públicos federais e estaduais, além de imagens de geoprocessamento referentes ao ano de 2019, disponibilizadas pelo site Map Biomas.

\section{UMA BREVE TRAJETÓRIA DA CRIAÇÃO DE ÁREAS PROTEGIDAS NO BRASIL E NO MUNDO}

Os valores românticos que inspiravam a sociedade do século XVIII refletiram na visão dos principais teóricos acerca do tema preservação da natureza, conhecidos como preservacionistas "puros" por conceberem a ideia de proteção integral do ambiente natural e da vida selvagem (FRANCO et al., 2015). De acordo com Diegues (2004), o preservacionismo pretende proteger a natureza contra o desenvolvimento moderno, industrial e urbano, tendo apoio científico na teoria da evolução de Darwin.

Exemplos práticos dessa corrente passaram a ser observados nos Estados Unidos, devido a degradação ambiental evidenciada durante um curto espaço de tempo, no leste do país. Nesse sentido, a primeira experiência de área de preservação mundialmente reconhecida foi o Parque Nacional de Yellowstone, localizado nos Estados Unidos, criado em 1872 e considerado um marco histórico para esse tipo de iniciativa.

Inspirados nesse modelo, outros países adotaram essa estratégia a partir da criação de áreas protegidas de grande beleza cênica e geralmente abertas ao público, como observado no Canadá (1885), seguido por Nova Zelândia e México (1894), África do Sul e Austrália (1898), Argentina (1903) e Chile (1926) (LEUZINGER, 2007; FRANCO et al., 2015). 
FOLI, A. C. A.; FARIA, K. M. S. de.

Oportunidades e Desafios da Criação de Unidades de Conservação: reflexões sobre as experiências no Estado de Goiás, Brasil.

À mesma época ocorria um debate sobre o uso racional dos recursos naturais de forma eficiente e democrática, visto ser observada a deterioração da qualidade de vida nos ambientes urbanos, visão que ficou conhecida por conservacionista (FRANCO et al., 2015).

Para Diegues (2004), o conservacionismo entende que os recursos naturais devem ser utilizados pela lógica do uso racional, a partir de três princípios: uso dos recursos pelas gerações presentes, prevenção de desperdício e uso dos recursos para benefício da maioria dos cidadãos. Como sugere Franco et al. (2015), a estratégia de criação de áreas protegidas que esse grupo propunha voltava-se ao manejo das florestas e o uso múltiplo dos recursos naturais.

Essas duas linhas teóricas norte-americanas de gestão territorial tiveram impacto sobre o pensamento dos intelectuais brasileiros durante boa parte do século XX. No entanto, durante o período Imperial no Brasil, a princípio, a visão preservacionista não se mostrou tão influente. Os intelectuais brasileiros atribuíram um caráter de conservação dos recursos naturais, não diminuindo a dimensão estética da natureza, porém, mais interessados em seu valor político e econômico, valendo-se do discurso do "progresso".

Nas décadas posteriores, as discussões advindas deste embate permitiram a institucionalização de algumas propostas no País, dentre elas o primeiro Código Florestal, primeiro Código de Águas e o Código de Caça e Pesca, promulgados entre os anos de 1933 e 1934. Também nesta década foram criados os primeiros Parques Nacionais, inspirados nos modelos norte-americanos: o do Itatiaia em 1937, e os do Iguaçu e Serra dos Órgãos, ambos em 1939.

Entre o período de 1934 a 1960 deve-se destacar um regime de proteção da natureza sob a responsabilidade da União, que culminou com a criação de quatro categorias de proteção ambiental: Floresta Protetora; Floresta Remanescente; Floresta de Rendimento; e, Floresta Modelo.

Como afirma Oliveira (2005, p. 47), o desenvolvimento da regulamentação ambiental no Brasil do século XX foi marcado por governos que seguiam os princípios da devastação ambiental, "ora em nome do desenvolvimento, ora em consequência do abandono do planejamento territorial; ora como fruto da integração nacional, ora como resultado da mais absoluta incúria administrativa". 
FOLI, A. C. A.; FARIA, K. M. S. de.

Oportunidades e Desafios da Criação de Unidades de Conservação: reflexões sobre as experiências no Estado de Goiás, Brasil.

Nesse sentido, é importante ressaltar que, conceitualmente, tanto os aspectos preservacionistas quanto os aspectos conservacionistas foram utilizados na elaboração de políticas de gestão ambiental do território. Até este momento, a falta de uma sistematização jurídica acerca das unidades de conservação no Brasil acarretava uma disposição de áreas aleatórias, sem a adoção de critérios mais rigorosos, especialmente em relação à participação das populações envolvidas (PEREIRA, 2005).

A partir de meados dos anos 1960, além das correntes preservacionistasconservacionistas surgiu a corrente de pensamento socioambientalista, buscando incluir no debate da criação de áreas protegidas a participação das populações envolvidas, visão que influenciou o pensamento teórico desde meados dos anos 1980 até os dias atuais. (FRANCO et al., 2015).

No Brasil, a criação do novo Código Florestal em 1965 estabeleceu melhor outros tipos de categorias de áreas protegidas, substituindo aquelas criadas no primeiro código pelas seguintes tipologias: Parque Nacional; Floresta Nacional; Áreas de Preservação Permanente (APP) e Reserva Legal (RL). Ainda na década de 1960 criou-se o Instituto Brasileiro de Desenvolvimento Federal - IBDF, com o objetivo de gerir as áreas protegidas existentes até aquele momento (FRANCO et al., 2015).

Sob este aspecto, o desenvolvimento e implementação dos Planos Nacionais de Desenvolvimento a partir dos anos 1970 culminou na criação da Secretaria Especial de Meio Ambiente - SEMA, responsável pela proposição de mais quatro categorias de áreas protegidas (Estações Ecológicas, Áreas de Proteção Ambiental, Reservas Ecológicas, Áreas de Relevante Interesse Ecológico; posteriormente foi criada a categoria de Reservas Particulares do Patrimônio Natural) e, também, foi responsável pela criação da Política Nacional de Meio Ambiente - PNMA em 1981.

No âmbito das mudanças mundiais associadas a percepção dos problemas ambientais, passou-se a observar maior mobilização entre as pessoas e a criação de uma agenda internacional em relação aos recursos naturais. A realização de conferências mundiais a respeito do meio ambiente tornou necessária a implantação de uma estrutura políticaorganizacional mais bem orientada para a conservação dos recursos naturais.

Sendo assim, baseado em Silva e Cunha (2010, p. 129), optou-se por destacar alguns dos principais eventos realizados no mundo visando aprimorar e traçar conceitos 
FOLI, A. C. A.; FARIA, K. M. S. de.

Oportunidades e Desafios da Criação de Unidades de Conservação: reflexões sobre as experiências no Estado de Goiás, Brasil.

acerca das áreas protegidas. É interessante notar que, a experiência adquirida nestas, e em outras conferências culminou na criação de organismos internacionais que buscam elaborar regulações acerca das áreas protegidas (Quadro 1).

Quadro 1: Principais conferências internacionais sobre a temática de áreas protegidas

\begin{tabular}{|l|c|c|}
\hline \multicolumn{1}{|c|}{ EVENTO } & LOCAL & ANO \\
\hline $\begin{array}{l}\text { Convenção para Preservação da Fauna e Flora em Estado } \\
\text { Natural; }\end{array}$ & Londres & 1933 \\
\hline $\begin{array}{l}\text { Convenção Pan-americana de Proteção de Natureza e } \\
\text { Preservação da Vida Selvagem do Hemisfério Oeste; }\end{array}$ & Washington & 1940 \\
\hline $\begin{array}{l}\text { Congresso organizado pelo governo francês e pela } \\
\text { Organização das Nações Unidas para a Educação, Ciência } \\
\text { e Cultura (UNESCO) - culminou na criação da IUCN; }\end{array}$ & Fontainebleau & 1948 \\
\hline Assembleias Anuais da IUCN & - & 1960 em diante \\
\hline Congresso Internacional de Parques Nacionais & Seattle, Yellowstone & 1962,1972 \\
\hline Congresso Internacional de Parques Nacionais & Bali (Indonésia) & 1982 \\
\hline Congresso Internacional de Parques Nacionais & Caracas (Venezuela) & 1992 \\
\hline
\end{tabular}

Fonte: SILVA; CUNHA, 2010.

A IUCN (The World Conservation Union) apresenta-se como um desses organismos, onde reúne mais de 1250 organizações, incluindo 84 governos nacionais, 112 agências governamentais, mais de 800 organizações não governamentais e mais de 10.000 cientistas e experts de 181 países. Foi desse organismo internacional que partiu a primeira formulação acerca de um modelo de sistema de unidades de conservação, buscando uma padronização mundial (SILVA; CUNHA, 2010; UICN, 2017).

A realização de conferências internacionais continuou mostrando-se bastante ativa, o que culminou na Declaração de Estocolmo em 1972. Posteriormente, a realização da Conferência das Nações Unidas sobre o Meio Ambiente e Desenvolvimento Sustentável, realizada no Rio de Janeiro em 1992 culminou em um tratado internacional das Nações Unidas: a Convenção sobre Diversidade Biológica - CDB (COELHO; REZENDE, 2016).

A partir de uma preocupação da UICN, a proteção aos meios de vida e à cultura das populações tradicionais buscando assegurar o uso sustentável dos recursos torna-se preocupação de Estado (GARCIA et al. 2018). Dessa forma, é importante enfatizar a elaboração da nova Constituição de 1988 que prevê, no artigo $225, \S 1^{\circ}$, parágrafo III

[...] definir, em todas as unidades da Federação, espaços territoriais e seus componentes a serem especialmente protegidos, sendo a alteração e a supressão 
FOLI, A. C. A.; FARIA, K. M. S. de.

Oportunidades e Desafios da Criação de Unidades de Conservação: reflexões sobre as experiências no Estado de Goiás, Brasil.

permitidas somente através de lei, vedada qualquer utilização que comprometa a integridade dos atributos que justifiquem sua proteção (BRASIL, 1988).

Deste momento em diante travou-se um intenso e longo debate políticojurisdicional para a regulamentação desse artigo. Nessa direção, somente nos anos 2000 instituiu-se o Sistema Nacional de Unidades de Conservação - SNUC, instrumento de gestão concebido para integrar, de forma sistemática, a criação e gestão das categorias de unidades de conservação no Brasil.

A Lei 9.985/2000 dispõe sobre as unidades de conservação, definidas como o

[...] espaço territorial e seus recursos ambientais, incluindo as águas jurisdicionais, com características naturais relevantes, legalmente instituído pelo Poder Público com objetivos de conservação e limites definidos, sob regime especial de administração ao qual se aplicam garantias adequadas de proteção (BRASIL, 2000).

Em seus aspectos institucionais, a gestão do SNUC é realizada com a participação do Conselho Nacional do Meio Ambiente - CONAMA, órgão consultivo e deliberativo; Ministério do Meio Ambiente - MMA, órgão com finalidade de coordenação do SNUC; e, nas esferas de execução conta com o apoio do Instituto Chico Mendes de Conservação da Biodiversidade (ICMBio) e Instituto Brasileiro do Meio Ambiente e Recursos Naturais IBAMA, além do auxílio de órgãos estaduais e municipais de meio ambiente.

Dessa maneira, o SNUC passou a ser um sistema reconhecido internacionalmente e considerado um dos modelos mais sofisticados de conservação da natureza do mundo, pois, além de incorporar parte das áreas protegidas já previstas pela legislação brasileira, também permitiu a criação de novas categorias, desenvolvidas no país a partir de experiências originais (GARCIA et al., 2018).

A criação de Unidades de Conservação no Brasil gera inúmeros benefícios. Medeiros e Young (2011) apontam que, 80\% das águas utilizadas por hidrelétricas brasileiras têm pelo menos um tributário à jusante de Unidade de Conservação; $9 \%$ da água utilizada para consumo humano é captada no interior de tais áreas protegidas; observa-se o aumento da conservação de mata ciliar e estabilização de encostas; além de verificar-se impactos econômicos favoráveis, associados ao desenvolvimento do turismo local, dentre outros. Atualmente consta no texto do SNUC a definição de 12 categorias de Unidades de 
FOLI, A. C. A.; FARIA, K. M. S. de.

Oportunidades e Desafios da Criação de Unidades de Conservação: reflexões sobre as experiências no Estado de Goiás, Brasil.

Conservação, reunidas em dois grupos: Unidades de Proteção Integral e Unidades de Uso Sustentável (Quadro 2).

Quadro 2: Categorias das Unidades de Conservação de acordo com o SNUC, 2000

\begin{tabular}{|c|c|}
\hline $\begin{array}{c}\text { Unidades de } \\
\text { Proteção Integral }\end{array}$ & Objetivo \\
\hline Estação Ecológica & Preservação da natureza e realização de pesquisas científicas. \\
\hline Reserva Biológica & $\begin{array}{l}\text { Preservação integral da biota e atributos naturais existentes em } \\
\text { seus limites, sem interferência humana direta ou modificações } \\
\text { ambientais. }\end{array}$ \\
\hline Parque Nacional & $\begin{array}{l}\text { Preservação de ecossistemas de grande relevância e beleza } \\
\text { cênica, sendo permitida a realização de pesquisas científicas e o } \\
\text { desenvolvimento de educação ambiental, de recreação e de } \\
\text { turismo ecológico. }\end{array}$ \\
\hline Monumento Natural & $\begin{array}{l}\text { Preservação de sítios naturais raros, singulares ou de grande } \\
\text { beleza cênica. }\end{array}$ \\
\hline Refúgio de Vida Silvestre & $\begin{array}{l}\text { Proteção de ambientes naturais onde se asseguram condições } \\
\text { para a existência ou reprodução de espécies ou comunidades da } \\
\text { flora local e da fauna residente ou migratória }\end{array}$ \\
\hline $\begin{array}{c}\text { Unidades de } \\
\text { Uso Sustentável }\end{array}$ & Objetivo \\
\hline Área de Proteção Ambiental & $\begin{array}{l}\text { Proteger a diversidade biológica, disciplinar o processo de } \\
\text { ocupação e assegurar a sustentabilidade dos recursos naturais. }\end{array}$ \\
\hline $\begin{array}{l}\text { Área de Relevante } \\
\text { Interesse Ecológico }\end{array}$ & $\begin{array}{l}\text { Manter os ecossistemas naturais de importância regional ou } \\
\text { local e regular o uso admissível dessas áreas. }\end{array}$ \\
\hline Floresta Nacional & $\begin{array}{l}\text { Uso múltiplo sustentável dos recursos florestais e a pesquisa } \\
\text { científica. }\end{array}$ \\
\hline Reserva Extrativista & Uso concedido às populações extrativistas tradicionais. \\
\hline Reserva de Fauna & $\begin{array}{l}\text { Área natural com populações animais de espécies nativas, } \\
\text { terrestres ou aquáticas, residentes ou migratórias. }\end{array}$ \\
\hline $\begin{array}{l}\text { Reserva de Desenvolvimento } \\
\text { Sustentável }\end{array}$ & Área natural que abriga populações tradicionais. \\
\hline $\begin{array}{c}\text { Reserva Particular do Patrimônio } \\
\text { Natural }\end{array}$ & $\begin{array}{l}\text { Área privada, gravada com perpetuidade, com o objetivo de } \\
\text { conservar a diversidade biológica. }\end{array}$ \\
\hline
\end{tabular}

De acordo com o Ministério do Meio Ambiente (2020) o Brasil adota as recomendações advindas da Convenção sobre Diversidade Biológica, e apresenta um relatório anual sobre a biodiversidade brasileira no Panorama da Biodiversidade Global. Nessa direção, o país elaborou Metas Nacionais de Biodiversidade em resposta às metas da CDB, das quais a Resolução CONABIO n 06, de 03 de setembro de 2013 previa, até o ano de 2020, conservação de $17 \%$ para todos os biomas, 30\% para a Amazônia e 10\% para ecossistemas marinhos. 
FOLI, A. C. A.; FARIA, K. M. S. de.

Oportunidades e Desafios da Criação de Unidades de Conservação: reflexões sobre as experiências no Estado de Goiás, Brasil.

As unidades de conservação da esfera federal do governo são administradas pelo Instituto Chico Mendes de Conservação da Biodiversidade (ICMBio). Nas esferas estadual e municipal as UCs são administradas por meio dos Sistemas Estaduais e Municipais de Unidades de Conservação.

Nesse sentido, conforme o exposto, no Brasil a criação de uma Unidade de Conservação é considerada a principal estratégia de Estado para conservar a biodiversidade e diminuir a aceleração da modificação da paisagem. Contudo, apenas o decreto não garante a efetivação dos objetivos de uma unidade de conservação, sendo necessário, ainda, a concreta implementação das mesmas, com níveis adequado de manejo (COELHO; REZENDE, 2016; GARCIA et al., 2018). Dessa maneira, acredita-se necessário compreender quais as oportunidades e os desafios enfrentados na criação de Unidades de Conservação no Estado de Goiás.

\section{OPORTUNIDADES E DESAFIOS DA CRIAÇÃO DE UNIDADES DE CONSERVAÇÃO EM GOIÁS}

É consenso entre os cientistas que a biodiversidade do planeta está conectada a heterogeneidade das paisagens terrestres e marinhas e devido à dinâmica de seu clima. Sendo assim, a biodiversidade é uma resposta evolutiva a esta diversidade de paisagens e climas para aumentar a chance de sobrevivência e adaptação das futuras gerações às incertezas espaciais e temporais de nosso planeta (DIAS, 2017).

O bioma Cerrado é considerado um dos hotspots mundiais para a conservação da biodiversidade, pois possui alta diversidade biológica e presta serviços ambientais essenciais na regulação do ciclo hidrológico, pois comporta as cabeceiras das principais bacias hidrográficas do Brasil. Além disso, do ponto de vista social, muitas populações sobrevivem a partir de seus recursos naturais e modos de vida, incluindo indígenas, quilombolas, ribeirinhos e outros que, juntos, fazem parte do patrimônio histórico e cultural brasileiro (MMA, 2020).

De fato, durante muito tempo, as características desse bioma foram menosprezadas do ponto de vista da conservação, o que pode ser atribuído, em partes, ao desconhecimento de sua relevância e à falta de estudos técnicos mais específicos. 
FOLI, A. C. A.; FARIA, K. M. S. de.

Oportunidades e Desafios da Criação de Unidades de Conservação: reflexões sobre as experiências no Estado de Goiás, Brasil.

O processo de degradação do Cerrado intensificou-se a partir da década de 1970, principalmente, por intermédio de políticas de expansão agropecuária e, em menor expressividade, devido ao crescimento das cidades nele localizadas. Dessa forma, verifica-se que a distribuição da flora, fauna, estado dos recursos hídricos e manutenção de serviços ecossistêmicos do bioma vêm sendo fortemente modificados em um curto espaço de tempo.

A região delimitada para o presente trabalho é o Estado de Goiás, por encontrar-se inserido no bioma Cerrado. O estado localiza-se na região Centro-Oeste do Brasil, ocupa uma área de 340.086 km² e limita-se ao norte com o Estado do Tocantins, ao sul com Minas Gerais e Mato Grosso do Sul, a leste com Bahia e Minas Gerais e a oeste com Mato Grosso. Goiás é banhado por quatro bacias hidrográficas: a Bacia do Rio Paranaíba, a Bacia do Rio Tocantins, a Bacia do Rio Araguaia e uma pequena porção da Bacia do Rio São Francisco (IBGE, 2020) (Figura 1).

Figura 1: Localização do Estado de Goiás

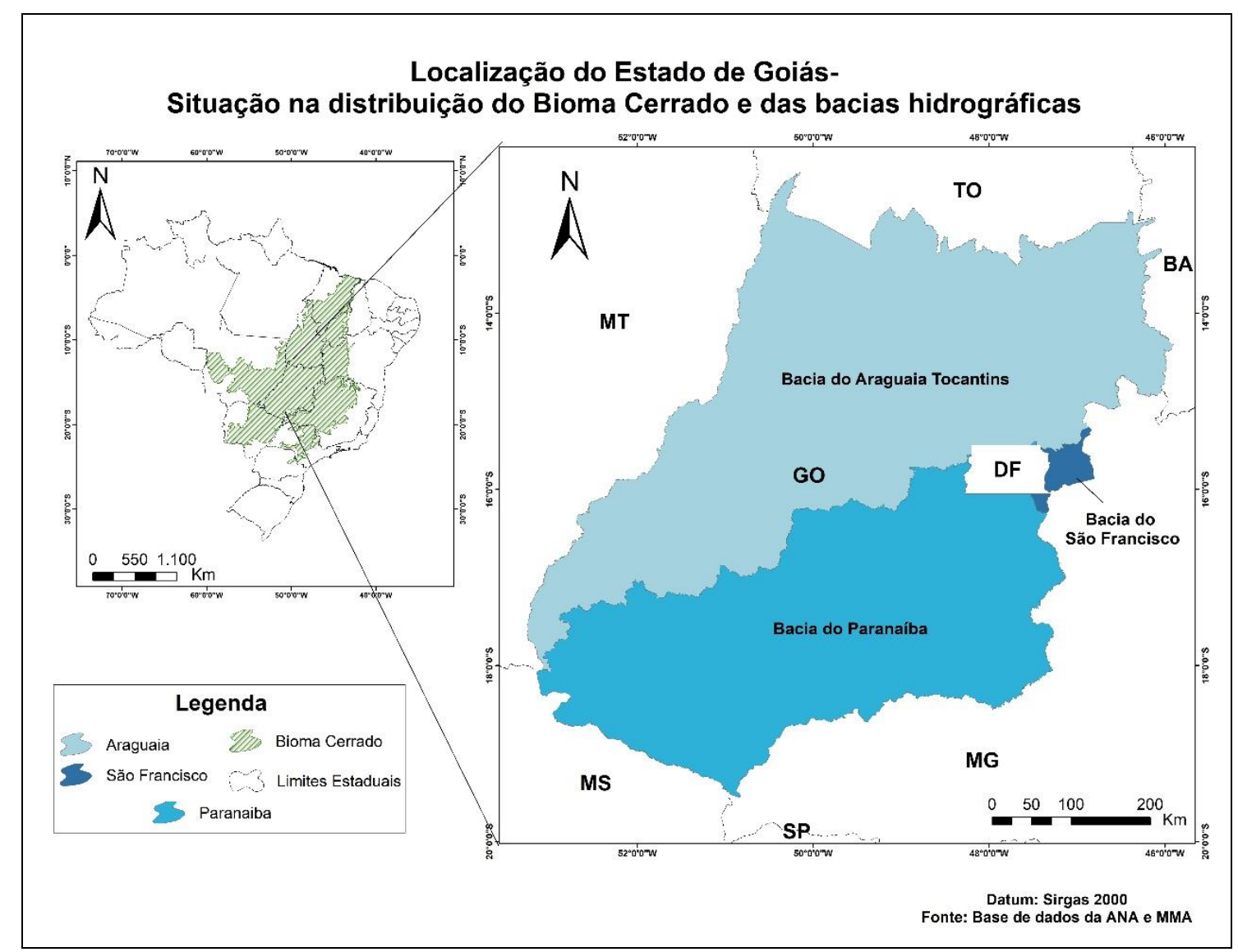

Fonte: ANA; MMA (2020). 
FOLI, A. C. A.; FARIA, K. M. S. de.

Oportunidades e Desafios da Criação de Unidades de Conservação: reflexões sobre as experiências no Estado de Goiás, Brasil.

Em relação a gestão dos recursos hídricos, os principais instrumentos normativos em Goiás são compostos pela Constituição Federal de 1988 e pela Constituição Estadual de Goiás de 1989. No âmbito da aprovação da Lei Federal nº 9.433/1997 sancionou-se a Lei Estadual no 13.123/1997, que instituiu a Política Estadual de Recursos Hídricos (CHAGAS et al., 2017).

Dados atualizados do Map Biomas (2020) sobre o uso e ocupação do solo no território goiano, referentes ao ano de 2019, apontam que a área de pastagem corresponde a 15.697.275,58 ha; a formação savânica abrange aproximadamente 6.237.418,32 ha; a formação florestal corresponde a 4.166.740,65 ha; a área de agricultura abrange 5.756.690,47 ha; a formação campestre corresponde a 1.370.093,64 ha, dentre outros usos (Figura 2).

Figura 2: Uso e Ocupação do Solo no Estado de Goiás em 2019

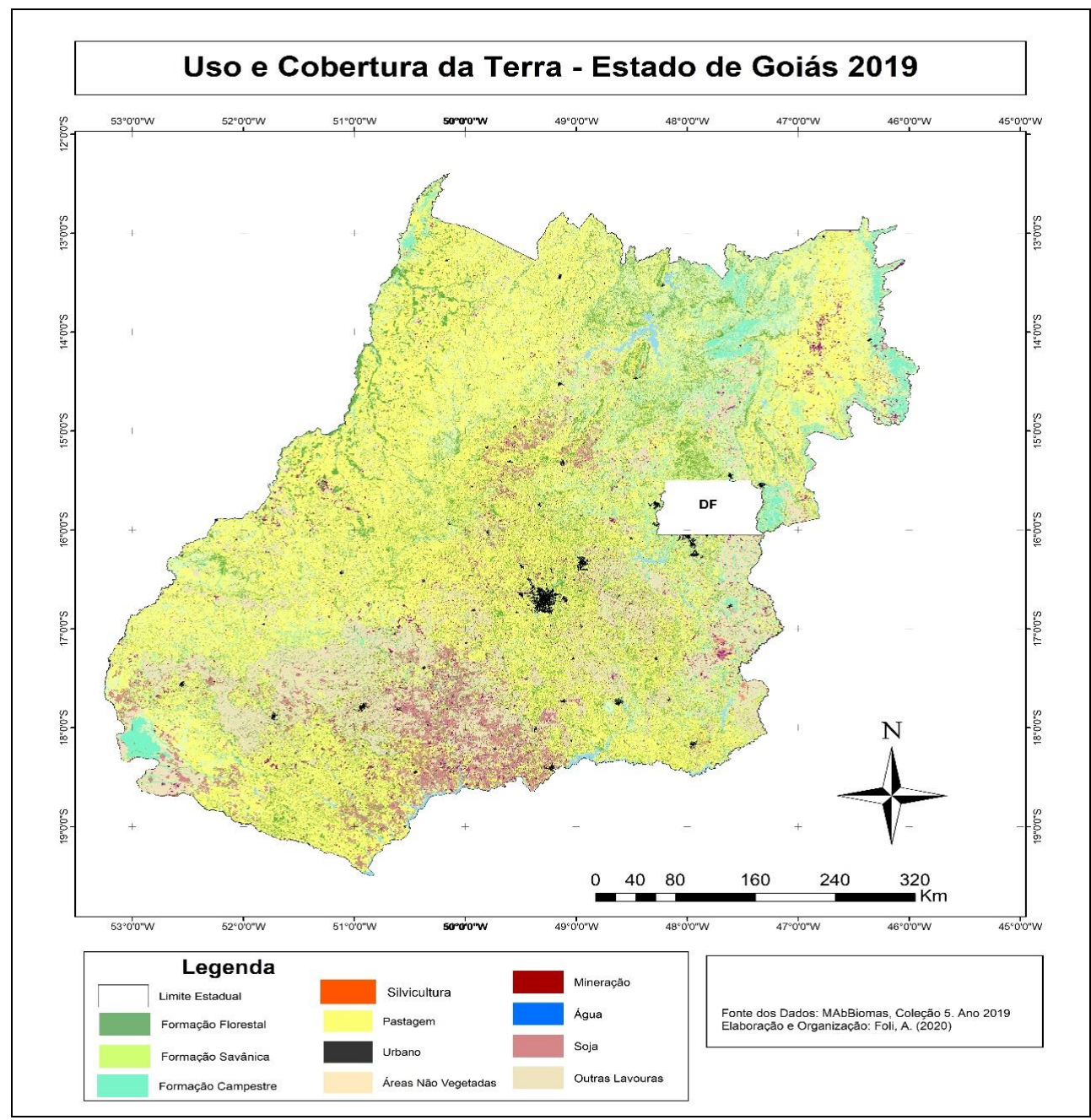

Fonte: MAP BIOMAS (2020).

Revista Cerrados, Montes Claros/MG, v. 18, n. 02, p. 424-446, jul./dez-2020. 
FOLI, A. C. A.; FARIA, K. M. S. de.

Oportunidades e Desafios da Criação de Unidades de Conservação: reflexões sobre as experiências no Estado de Goiás, Brasil.

Sob este aspecto, observa-se na Figura 2 que a área de pastagem abrange a maior parte do estado. As áreas de cultivo anual e perene concentram-se na parte sul e sudoeste de Goiás, devido as características topográficas e pedológicas mais favoráveis, contudo, verificase enclaves que vão de sudeste a nordeste do estado, demonstrando o avanço da agropecuária nessas áreas. As formações savânicas, florestais e campestres são observadas de modo bastante significativo no norte e nordeste do estado e, em menor proeminência, próximas aos cursos d'água.

De acordo com o Ministério do Meio Ambiente (2015), a utilização de Unidades de Conservação como instrumento de política ambiental no Estado de Goiás iniciou-se no ano de 1959, com a criação pelo Governo Federal do Parque Nacional do Araguaia, hoje situado no Estado do Tocantins.

A regulamentação sobre unidades de conservação em Goiás foi instituída pela Lei Estadual $n^{\circ} 14.247 / 2002$ e pelo Decreto Estadual $n^{\circ} 5.806 / 2003$, criando o Sistema Estadual de Unidades de Conservação (SEUC). Atualmente, a Lei Estadual n ${ }^{\circ}$ 18.104/2013 dispõe sobre a Política Florestal do Estado de Goiás, que normatiza as áreas de conservação e prioriza os corretos usos do solo e dos recursos hídricos (SOARES et al., 2017). Sendo assim, em Goiás, a criação de uma UC Estadual ou Municipal envolve as seguintes etapas:

1. Realização de estudos técnicos: para identificar os aspectos naturais e culturais da unidade de conservação e seu entorno, conforme as diretrizes da Resolução CEMAm n ${ }^{\circ}$ 006/2016;

2. Realização de consulta pública: reunião com a população local e outras partes interessadas para apresentação de estudos técnicos, conforme as diretrizes da Resolução CEMAm nº 007/2016;

3. Instituição Legal da Unidade: o ato legal de criação de unidade de conservação, com a publicação de lei ou decreto. (SEMAD, 2020, grifo do autor).

De acordo com o Painel das Unidades de Conservação Brasileiras - PUCB (2020), Goiás possui 133 unidades de conservação, com uma área total protegida de 1.903.403ha ou 19.034,03 km² (Figura 3). A área de UCs corresponde a 4,62\% do território goiano, o equivalente a $0,22 \%$ de área continental protegida a nível nacional.

Goiás possui dois parques nacionais: o Parque Nacional das Emas, localizado em Mineiros, e o Parque Nacional da Chapada dos Veadeiros, em Alto Paraíso de Goiás, ambos instituídos no ano de 1961. O Estado conta, ainda, com 4 unidades de conservação de uso sustentável de domínio federal, e 23 unidades municipais (PUCB, 2020). 
FOLI, A. C. A.; FARIA, K. M. S. de.

Oportunidades e Desafios da Criação de Unidades de Conservação: reflexões sobre as experiências no Estado de Goiás, Brasil.

Figura 3: Localização das UCs no Estado de Goiás e entorno próximo

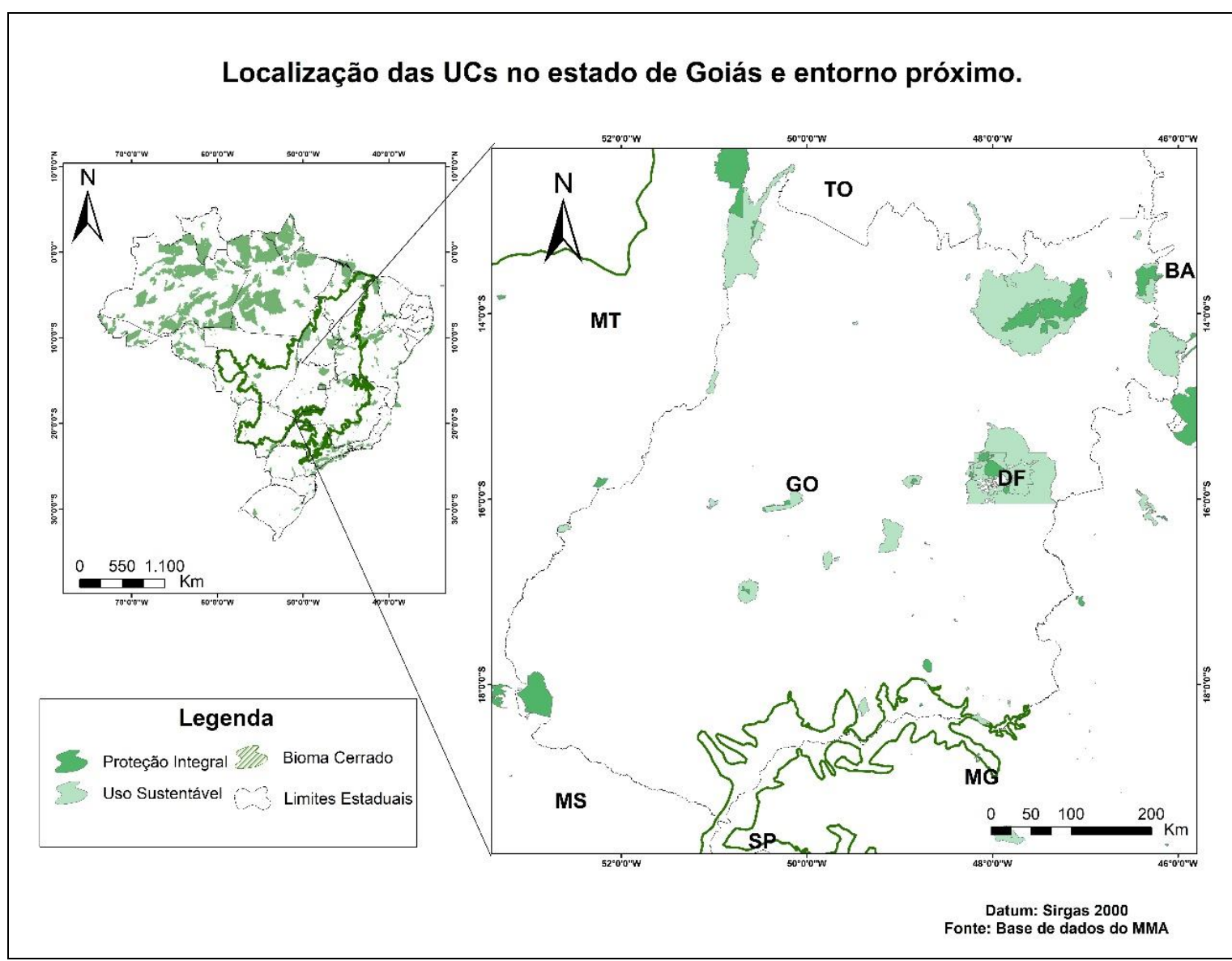

Fonte: MMA (2020).

Além disso, o estado congrega 61 Reservas Particulares do Patrimônio Natural RPPN's, que englobam diferentes fitofisionomias do Cerrado. O aumento dessas áreas se deu em função de incentivos fiscais e tributários, o que pode ter contribuído para a conservação da biodiversidade em Goiás.

De acordo com o PUCB (2020), existem 24 unidades de conservação a nível estadual, sendo 13 pertencentes ao grupo de proteção integral (12 parques e uma estação ecológica), e 11 ao grupo de uso sustentável (9 áreas de proteção ambiental, 1 floresta estadual e 1 área de relevante interesse ecológico) (Quadros 3 e 4).

A criação e ampliação de Unidades de Conservação tem sido crescente nos últimos anos. Há que se reconhecer os esforços que Brasil tem empreendido na criação de UCs, tendo sido o país que, na primeira década deste século, mais ampliou o sistema de áreas 
FOLI, A. C. A.; FARIA, K. M. S. de.

Oportunidades e Desafios da Criação de Unidades de Conservação: reflexões sobre as experiências no Estado de Goiás, Brasil.

protegidas no mundo (DIAS, 2017). Esta assertiva é corroborada pelos dados das UCs do estado de Goiás, apresentados nos Quadros 3 e 4.

Quadro 3: Unidades de Proteção Integral no Estado de Goiás

\begin{tabular}{|l|c|c|c|}
\hline \multicolumn{1}{|c|}{ Unidades de Proteção Integral } & $\begin{array}{c}\text { Ano de } \\
\text { Criação }\end{array}$ & $\begin{array}{c}\text { Plano de } \\
\text { Manejo }\end{array}$ & $\begin{array}{c}\text { Conselho } \\
\text { Gestor }\end{array}$ \\
\hline Parque Estadual da Serra de Caldas Novas & 1970 & Sim & Não \\
\hline Parque Estadual dos Pirineus & 1987 & Não & Sim \\
\hline Parque Estadual de Terra Ronca & 1989 & Não & Não \\
\hline Parque Estadual Altamiro de Paula Pacheco & 1992 & Não & Não \\
\hline Parque Estadual Telma Ortegal & 1995 & Não & Não \\
\hline Parque Estadual da Serra de Jaraguá & 1998 & Não & Não \\
\hline Parque Estadual de Paraúna & 2002 & Não & Não \\
\hline Parque Estadual do Araguaia & 2002 & Não & Não \\
\hline Parque Estadual da Serra Dourada & 2003 & Não & Sim \\
\hline Parque Estadual do Descoberto & 2005 & Não & Sim \\
\hline Parque Estadual da Mata Atlântica & 2006 & Não & Não \\
\hline Parque Estadual do João Leite & 2014 & Não & \\
\hline Estação Ecológica da Chapada de Nova Roma & 2017 & Sim & Sim \\
\hline Parque Estadual de Águas Lindas & 2019 & Não & Sim \\
\hline Âmbito Federal & & & Sim \\
\hline Parque Nacional Chapada dos Veadeiros & 1961 & Sim & \\
\hline Parque Nacional das Emas & 1961 & & \\
\hline
\end{tabular}

Fonte: PUCB (2020).

Quadro 4: Unidades de Uso Sustentável no Estado de Goiás

\begin{tabular}{|l|c|c|c|}
\hline \multicolumn{1}{|c|}{ Unidades de Uso Sustentável } & Ano de Criação & Plano de Manejo & Conselho Gestor \\
\hline APA Serra Geral de Goiás & 1996 & Não & Não \\
\hline APA da Serra Dourada & 1998 & Não & Não \\
\hline APA dos Pireneus & 2000 & Não & Não \\
\hline APA da Serra da Jiboia & 2000 & Não & Não \\
\hline ARIE Águas de São João & 2000 & Não & Sim \\
\hline APA do Pouso Alto & 2001 & Sim & Não \\
\hline APA das Nascentes do Rio Vermelho & 2001 & Não & Não \\
\hline APA das Serras da Galé e da Portaria & 2002 & Não & Não \\
\hline APA do João Leite & 2002 & Não & Não \\
\hline Floresta Estadual do Araguaia & 2002 & Não & Sim \\
\hline APA do Encantado & 2003 & Não & Não \\
\hline Âmbito Federal & & & Sim \\
\hline Floresta Nacional de Silvânia & 1949 & Não & Não \\
\hline Floresta Nacional da Mata Grande & 2003 & Não & Não \\
\hline Resex Lago dos Cedros & 2006 & Não & \\
\hline Resex Recanto das Araras & 2006 & & \\
\hline
\end{tabular}

Fonte: PUCB (2020).

As áreas de Unidade de Proteção Integral no Estado de Goiás correspondem a $16,81 \%$ do total, enquanto as áreas de Unidade de Uso Sustentável correspondem a 83,19\%. 
FOLI, A. C. A.; FARIA, K. M. S. de.

Oportunidades e Desafios da Criação de Unidades de Conservação: reflexões sobre as experiências no Estado de Goiás, Brasil.

Em relação a modalidade de gestão, 46,02\% são da categoria de gestão pública, e 53,98\% de gestão privada, o que pode estar relacionado ao aumento do número de RPPN's cadastradas nos últimos anos (PUCB, 2020). Apenas 10,62\% do total das UCs possui Conselho Gestor e, cerca de $96,4 \%$ não possui Plano de Manejo.

Em relação às Unidades de Proteção Integral, apenas o Parque Estadual da Serra de Caldas Novas, unidade criada em 1970, e a Estação Ecológica da Chapada de Nova Roma, criada em 2017, possuem Plano de Manejo; já o Parque Estadual de Terra Ronca, o Parque Estadual do João Leite e a Estação Ecológica da Chapada de Nova Roma são as únicas unidades que possuem Conselho Gestor. Os dois parques nacionais do Estado possuem ambos.

Em relação às Unidades de Uso Sustentável pertencentes a esfera administrativa estadual, apenas a APA do Pouso Alto possui plano de manejo, o que pode ser considerado muito grave do ponto de vista legislacional, visto que, após a criação de uma unidade de conservação, o plano de manejo deve ser elaborado em um prazo máximo de cinco anos. Como salienta o SNUC em seu artigo 27, todas as categorias de UCs devem dispor de planos de manejo, pois este constitui-se um documento de grande eficácia para a gestão da unidade (MEDA, 2014).

A primeira unidade nessa categoria, a Área de Proteção Ambiental - APA da Serra Geral de Goiás foi criada ainda no ano de 1996. Já a APA do Pouso Alto e a APA das Nascentes do Rio Vermelho, ambas criadas em 2001, são as únicas que possuem Conselho Gestor. A ausência de conselhos gestores em grande parte das UCs no Estado implica em menor envolvimento da sociedade civil nas tomadas de decisão.

Atualmente, Goiás é uma das unidades da federação com menor índice de áreas legalmente protegidas, cerca de 4,62\% do total de UCs no território brasileiro (PUBC, 2020). Sendo assim, não há como desvincular a compreensão sobre as oportunidades de criação das UCs sem que se considere os desafios impostos ao território, especialmente nas últimas décadas.

Goiás apresenta elevado nível de desmatamento desde a criação de Brasília, da abertura de estradas na década de 1960, e da expansão agrícola a partir da década de 1970 (BROCHADO, 2014). Nos últimos anos, o Cerrado tem sofrido ainda mais com o nível 
FOLI, A. C. A.; FARIA, K. M. S. de.

Oportunidades e Desafios da Criação de Unidades de Conservação: reflexões sobre as experiências no Estado de Goiás, Brasil.

elevado de desmatamento e queimadas que resultam de monitoramentos e ações públicas inadequadas para a realidade da região.

Relatório recém atualizado e disponibilizado pelo projeto Map Biomas (2020) aponta o Cerrado como o segundo maior bioma em área devastada, com a perda de 408,6 mil hectares. Apesar dos recentes esforços de pesquisadores e órgãos ambientais em identificar áreas prioritárias para a conservação do Cerrado, os resultados não têm sido suficientes para conter a atual tendência de aumento da degradação ambiental (SCARAMUZZI et al., 2005).

A vegetação do bioma é responsável pela alimentação de lençóis profundos devido ao seu sistema radicular bastante complexo (ARENS, 1958; AB'SABER, 1983). Dessa forma, é importante compreender a relação entre vegetação e recursos hídricos, pois no Cerrado encontram-se três grandes aquíferos responsáveis pela formação e alimentação de grandes rios continentais. A substituição da vegetação natural por monoculturas impacta diretamente no funcionamento dos corpos hídricos, pois as raízes subsuperficiais não sugam as águas como as plantas nativas o que, eventualmente, diminui a capacidade hídrica (BARBOSA, 2014).

Sob este aspecto, os conflitos entre os interesses econômicos oriundos da posse fundiária e a necessidade de conservação da biodiversidade no Cerrado são rotineiros (SANTOS; NUNES, 2015). Dessa forma, ONGs, agências governamentais, institutos estaduais e federais, e universidades têm buscado fortalecer o diálogo e aumentar o número de pesquisas no Cerrado em conjunto com as populações tradicionais existentes no território.

Nesse sentido, duas experiências de UCs em Goiás demonstram o exemplo deste tipo de articulação: o Parque Nacional da Chapada dos Veadeiros, unidade de uso de proteção integral que vem ganhando destaque nos últimos anos, principalmente em relação ao turismo ecológico e "esotérico"; e, a APA do Pouso Alto, única unidade de uso sustentável a apresentar plano de manejo A população no entorno de ambas as unidades apresenta maior participação na tomada de decisões devido possuir maiores informações sobre o território, utilizando-se desse aporte em busca de um uso mais sustentável dos recursos naturais.

Entretanto, conforme verificado nos quadros 3 e 4, a grande questão a ser enfrentada em Goiás não se trata apenas da criação de UCs, e sim, sua efetiva implantação, com planos de manejo adequados a cada uma. A falta desta ferramenta de gestão implica em uma série de questões que comprometem a conservação e manutenção dos ambientes. 
FOLI, A. C. A.; FARIA, K. M. S. de.

Oportunidades e Desafios da Criação de Unidades de Conservação: reflexões sobre as experiências no Estado de Goiás, Brasil.

Ademais, a ausência de Conselho Gestor nas UCs é um fator extremamente prejudicial, visto que, para além de se reconhecer a importância dos componentes naturais do espaço, faz-se necessário o posicionamento crítico e a participação colaborativa das populações envolvidas neste processo (OLIVEIRA, 2016).

Outro fator bastante menosprezado em termos de legislação tem sido a gestão das águas. Na literatura quase não há referências nos planos de manejo sobre recursos hídricos subterrâneos, que apresentam extrema relevância para o Cerrado. Ainda, observa-se pouca ou nenhuma articulação entre os Comitês de Bacias Hidrográficas e os Conselhos Gestores, pois estes praticamente inexistem. Portanto, pressupõe-se que a integração entre gestão de Unidades de Conservação e gestão de Recursos Hídricos apresentaria melhores resultados em termos de eficiência, equidade e estética das áreas protegidas.

Corroborando o que foi exposto, em estudo realizado por Santos e Nunes (2015) verificou-se o atraso do ordenamento e fiscalização do uso do solo em Goiás derivado do impacto da não efetivação de planos de manejo em UCs de uso sustentável, o que foi evidenciado pela presença de atividades antrópicas, principalmente em APPs de cursos d'água e de topos de morro. Já no interior das UCs de proteção integral, onde a fiscalização se faz mais presente, com critérios de ocupação restritos, pôde-se constatar uma maior plenitude na conservação de ambas as categorias de APPs.

\section{CONSIDERAÇÕES FINAIS}

É evidente que os impactos à biodiversidade seriam maiores se os governos não tivessem investido na criação de Unidades de Conservação no Brasil. Contudo, muitas dessas áreas existem apenas no papel, pois não apresentam conselho gestor ou plano de manejo, sem que, na prática, qualquer ação de preservação ou conservação seja efetivada.

Nesse sentido, verifica-se a necessidade de maior gerenciamento das áreas protegidas em Goiás, com a efetiva implantação dos planos de manejo e a criação de conselhos gestores; integração entre a gestão das unidades de conservação e a gestão de recursos hídricos; de investimento financeiro melhor direcionado; parceria com atores nos âmbitos privado e comunitário; e, o fortalecimento de grupos e atores locais. 
FOLI, A. C. A.; FARIA, K. M. S. de.

Oportunidades e Desafios da Criação de Unidades de Conservação: reflexões sobre as experiências no Estado de Goiás, Brasil.

Além disso, é necessário considerar as mudanças ambientais globais (fragmentação e degradação dos ecossistemas, poluição, aumento de espécies invasores e exóticas) acopladas às mudanças climáticas, orientando melhor o debate. Dessa forma, a biodiversidade pode ser vista como um seguro contra as incertezas e os riscos a que todos os seres vivos estamos expostos, portanto, os esforços têm de se voltar em conservar as espécies e diversidade genética que temos agora, no presente.

As atuais metas globais de conservação da biodiversidade são estipuladas com o reconhecimento histórico da real dependência da atual sociedade, assim como para as demais gerações. O Brasil, assim como outros países em zonas tropicais, tem papel importante no atendimento das metas ambientais, mas, além de atender os acordos internacionais já retificados, o país demanda real atenção às condições ambientais, tendo em vista que as degradações ambientais rapidamente afetam a qualidade social e econômica.

A postura que o Brasil assume quanto ao não atendimento das metas tem, inclusive, reflexos internacionais, com um papel determinante na agenda ambiental global. É necessário que o país avance em sua agenda de conservação da biodiversidade, indicada nos acordos já retificados, e ajude outras nações a elevarem suas metas, ou o Brasil vai fracassar e levar consigo todo um esforço de décadas na evolução desse debate.

\section{REFERÊNCIAS}

AB'SABER, A. N. O domínio do Cerrado: introdução ao conhecimento. Revista do Serviço Público, Brasília, v. 40, n. 4, p. 41-56, 1983.

ARENS, K. O Cerrado como vegetação oligotrófica. Revista Botânica, São Paulo, v. 224, n. 15, p. $57-78,1958$.

BARBOSA, A. S. A complexa teia hídrica que brota do Cerrado está ameaçada. Portal Ecodebate. Disponível em: https://www.ecodebate.com.br/2014/10/27/a-complexa-teiahidrica-que-brota-do-cerrado-esta-ameacada-entrevista-com-altair-sales-barbosa. Acesso em: 22 julho 2020.

BARROS, A. C. A construção da política nacional de áreas protegidas fortalecendo as estratégias de conservação, uso e repartição de benefícios da biodiversidade no Brasil. In:

Anais do IV Congresso Brasileiro de Unidades de Conservação, vol. 2. Curitiba, Fundação O Boticário de Proteção à Natureza \& Rede Pró-Unidades de Conservação, p. 177-186, 2004. BRASIL. Constituição (1988). Constituição da República Federativa do Brasil. Brasília, DF: Senado Federal: Centro Gráfico, 1988. Disponível em: 
FOLI, A. C. A.; FARIA, K. M. S. de.

Oportunidades e Desafios da Criação de Unidades de Conservação: reflexões sobre as experiências no Estado de Goiás, Brasil.

http://www.planalto.gov.br/ccivil_03/constituicao/constituicao.htm. Acesso em: 19 julho 2020.

BRASIL. Lei no 9.985, de 18 de julho de 2000. Institui o Sistema Nacional de Unidades de Conservação da Natureza - SNUC. Brasília, DF. Disponível em:

http://www.planalto.gov.br/ccivil_03/leis/19985.htm. Acesso em: 18 julho 2020.

BROCHADO, M. L. C. Análise de cenário de desmatamento para o estado de Goiás. 2014. 58 f. Trabalho de Conclusão de Curso (Graduação em Engenharia Florestal). Faculdade de Tecnologia, Departamento de Engenharia Florestal, Universidade de Brasília, Brasília, 2014.

CHAGAS, A. H. B.; LEAL, A. C.; CAMPOS, F. I.; PEIXOTO, J. C.; GIUSTINA, C. C. D. Gestão das Águas no Estado de Goiás: perspectivas para a participação da Universidade na instalação e atuação do Comitê das Bacias Hidrográficas do Rio Almas e Afluentes Goianos do Rio Maranhão. Revista Fronteiras, Anápolis, v. 6, n. 2, p. 147-166, 2017. Disponível em: http://periodicos.unievangelica.edu.br/index.php/fronteiras. Acesso em: 05 ago 2020.

COELHO, H. A.; REZENDE, E. N. A efetiva implantação das Unidades de Conservação ambiental por meio da desapropriação. Revista da Faculdade de Direito da UFG, v. 40, n. 1, p. 146-165, jan./jun. 2016. Disponível em: https://www.revistas.ufg.br/revfd/article/view/38078. Acesso em: 07 julho 2020.

DIAS, B. As Unidades de Conservação no Brasil, Biodiversidade e os Acordos Internacionais. Vídeo (Palestra). Canal Mídia e Amazônia. In: Unidades de Conservação no Brasil: ameaças, retrocessos e o futuro do SNUC. Disponível em: https://www.youtube.com/watch?v=fx0TixHhWB4. Acesso em: 24 julho 2020.

DIEGUES, A. C. O mito moderno da natureza intocada. 4. ed. São Paulo: Hucitec, 2004, $168 \mathrm{p}$.

FRANCO, J. L.; SCHIRRINI, G. M.; BRAZ, V. S. História da Conservação da Natureza e das Áreas Protegidas: Panorama Geral. Historiae, Rio Grande, v.6, n. 2, p. 233-270, 2015. Disponível em: https://periodicos.furg.br/hist/article/view/5594. Acesso em: 13 ago 2020.

GARCIA, L. V. M.; MOREIRA, J. C.; BURNS, R. C. Conceitos Geográficos na Gestão das Unidades de Conservação Brasileiras. GEOgraphia, Niterói, Universidade Federal Fluminense v. 20, n. 42, jan. /abr., 2018. Disponível em:

https://periodicos.uff.br/geographia/article/view/13832. Acesso em: 14 ago 2020.

GOIÁS. Lei no 14.247, de 29 de julho de 2002. Institui o Sistema de Unidades de Conservação no Estado de Goiás e dá outras providências. Disponível em:

https://legisla.casacivil.go.gov.br/pesquisa_legislacao/81809/lei-14247. Acesso em: 12 ago . 2020.

INSTITUTO BRASILEIRO DE GEOGRAFIA E ESTATÍSTICA - IBGE. Cidades e

Estados. Disponível em: https://www.ibge.gov.br/cidades-e-estados/go.html. Acesso em: 22 julho 2020 . 
FOLI, A. C. A.; FARIA, K. M. S. de.

Oportunidades e Desafios da Criação de Unidades de Conservação: reflexões sobre as experiências no Estado de Goiás, Brasil.

LEUZINGER, M. D. Natureza e Cultura: direito ao meio ambiente equilibrado e direitos culturais diante da criação de unidades de conservação de proteção integral e domínio público habitadas por populações tradicionais. 2007. 357 f. Tese (Doutorado em Desenvolvimento Sustentável). Universidade de Brasília, Brasília, 2007.

MAP BIOMAS BRASIL. Coleção 5. Disponível em: https://plataforma.mapbiomas.org. Acesso em: 23 out. 2020.

MEDA, R. V. A criação de Unidades de Conservação no reconhecimento de territórios às populações tradicionais. Revista de Direito da Cidade, Rio de Janeiro, Universidade Estadual do Rio de Janeiro, v. 6, n. 1, p. 275-300, 2014. Disponível em: https://www.epublicacoes.uerj.br/index.php/rdc/article/view/11346/8966. Acesso em: 28 de ago. 2020.

MEDEIROS, R. A Proteção da Natureza: das estratégias internacionais e nacionais às demandas locais. 2003. 391 f. Tese (Doutorado em Geografia). Programa de Pós-Graduação em Geografia, Universidade Federal do Rio de Janeiro, Rio de Janeiro, 2003.

MEDEIROS, R. Evolução das Tipologias e Categorias de Áreas Protegidas no Brasil. Revista Ambiente \& Sociedade, Campinas, v. 9, n. 1, p. 41-64, jan/jul 2006. Disponível em: https://www.scielo.br/pdf/asoc/v9n1/a03v9n1.pdf. Acesso em 14 de abril de 2020.

MEDEIROS, R.; YOUNG, C. E. F. Contribuição das unidades de conservação brasileiras para a economia nacional. Brasília: Unep/WCMC, 2011, 120 p.

MINISTÉRIO DO MEIO AMBIENTE - MMA. Parque Nacional do Araguaia. Disponível em: https://www.mma.gov.br/informma/item/12577-noticia-acom-2015-01-712.html. Acesso em: 19 julho 2020.

MINISTÉRIO DO MEIO AMBIENTE - MMA. Biodiversidade. Disponível em: https://www.mma.gov.br/biodiversidade.html. Acesso em: 19 julho 2020.

MINISTÉRIO DO MEIO AMBIENTE - MMA. Cadastro Nacional de Unidades de Conservação. Área das Unidades de Conservação de acordo com o SNUC por tipo, categoria e esfera. Disponível em: www.mma.gov.br/areas-protegidas/cadastro-nacional-deucs.html. Acesso em: 24 julho 2020.

OLIVEIRA, I. A. Gestão de conflitos em parques: estudo de caso do entorno nordeste do Parque Estadual da Serra do Tabuleiro. 2005. 269 f. Tese (Doutorado em Engenharia da Produção). Programa de Pós-Graduação em Engenharia de Produção, Universidade Federal de Santa Catarina, Florianópolis, 2005.

OLIVEIRA, A. S. de. Os dilemas socioambientais no entorno do Parque Nacional da Chapada dos Veadeiros: uma análise pela perspectiva crítica da Educação Ambiental. 2016. 167 f. Tese (Doutorado em Ciências Ambientais). Instituto de Ciências Biológicas, Universidade Federal de Goiás, Goiânia, 2016.

PAINEL DAS UNIDADES DE CONSERVAÇÃO BRASILEIRAS - PUCB. Dados das unidades de conservação cadastradas no estado de Goiás. Disponível em: 
FOLI, A. C. A.; FARIA, K. M. S. de.

Oportunidades e Desafios da Criação de Unidades de Conservação: reflexões sobre as experiências no Estado de Goiás, Brasil.

https://app.powerbi.com/view?r=eyJrIjoiMjUxMTU0NWMtODkyNC00NzNiLWJiNTQtNGI 3NTI2NjliZDkzIiwidCI6IjM5NTdhMzY3LTZkMzgtNGMxZi1hNGJhLTMzZThmM2M1NT BlNyJ9. Acesso em: 26 julho 2020.

PEREIRA, D. B. Paradoxos do papel do Estado nas Unidades de Conservação. In.: ZHOURI, A. (Org.). A insustentável leveza da política ambiental: desenvolvimento e conflitos socioambientais. Belo Horizonte: Autêntica, 2005.

SANTOS, S. A. dos. NUNES, F. G. Mapeamento do conflito de uso legal da terra nas unidades de conservação (UCs) da Reserva da Biosfera do Cerrado: nordeste de Goiás. In: Anais XVII Simpósio Brasileiro de Sensoriamento Remoto, João Pessoa, 25 a 29 de abril de 2015, p. 933-940.

SCARAMUZZA, C. A. de M.; MACHADO, R. B.; RODRIGUES, S. T.; RAMOS NETO, M. B.; PINAGÉ, E. R.; DINIZ FILHO, J. A. F. Áreas Prioritárias para Conservação da Biodiversidade em Goiás. In.: FERREIRA, L. G. (Ed.). Conservação da biodiversidade e sustentabilidade ambiental em Goiás: Prioridades, estratégias e perspectivas. Goiânia, 2005, 192 p.

\section{SECRETARIA DE ESTADO DE MEIO AMBIENTE E DESENVOLVIMENTO} SUSTENTÁVEL - SEMAD. Unidades de Conservação. Disponível em https://www.meioambiente.go.gov.br. Acesso em: 20 julho 2020.

SILVA, J. I. A. O.; CUNHA, L. H. Regime Jurídico das Unidades de Conservação: suas características jurídico-ambientais. Revista Dat@venia, Campina Grande, v. 2, n. 1, p. 121143, jan./jun. 2010. Disponível em:

http://revista.uepb.edu.br/index.php/datavenia/article/view/121-143. Acesso em: 28 julho 2020.

SOARES, F. B.; SANTOS, R. dos; BARBALHO, M. G. S.; PEIXOTO, J. C.; LEAL, A. C. Unidades de Conservação no estado de Goiás: potencial para áreas de proteção integral na microrregião de Ceres. In: Anais VIII Simpósio Nacional de Ciência e Meio Ambiente, Anápolis, 23 a 27 de outubro de 2017. Disponível em: http://anais.unievangelica.edu.br/index.php/sncma/article/view/10. Acesso em: 26 ago.2020.

UNIÃO INTERNACIONAL DE CONSERVAÇÃO PARA A NATUREZA - UICN. Governança de Áreas Protegidas: da compreensão à ação. Série Diretrizes para melhores Práticas para Áreas Protegidas, n. 20, Gland, Suíça: UICN, 2017, 124 p.

UNIÃO INTERNACIONAL DE CONSERVAÇÃO PARA A NATUREZA - UICN. Notícias, 2019. Disponível em: https://www.iucn.org/pt/news/secretariat/201908/a-uicnuniao-internacional-para-a-conservacao-da-natureza-convoca-o-governo-brasileiro-e-outrosgovernos-e-cidadaos-a-se-unirem-para-acabar-com-os-incendios-naamazonia\#: :text=\%C3\%89\%20necess\%C3\%A1rio\%20reconhecer\%20que\%20as, guardi\%C 3\%B5es\%20eficazes\%20da\%20riqueza\%20amaz\%C3\%B4nica. Acesso em: 12 ago. 2020. 
FOLI, A. C. A.; FARIA, K. M. S. de.

Oportunidades e Desafios da Criação de Unidades de Conservação: reflexões sobre as experiências no Estado de Goiás, Brasil.

WWF BRASIL. Criação de Áreas Protegidas. Disponível em:

https://www.wwf.org.br/natureza_brasileira/areas_prioritarias/amazonia1/nossas_solucoes_na _amazonia/areas_protegidas_na_amazonia/criacao_de_areas_protegidas_na_amazonia.

Acesso em: 22 julho 2020.

\section{Autoras}

Ana Cristina Araújo Foli - É Graduada em Geografia pela Universidade Federal de Uberlândia (UFU) e Mestre em Geografia pela Universidade Federal de Goiás (UFG). Atualmente é Doutoranda pelo Programa de Pós-Graduação em Geografia (PPGEO) do Instituto de Estudos Socioambientais (IESA), da Universidade Federal de Goiás (UFG).

Karla Maria Silva de Faria - É Graduada, Mestre e Doutora em Geografia pela Universidade Federal de Goiás (UFG). Atualmente é Docente vinculada ao Programa de PósGraduação em Ciências Ambientais (CIAMB) e ao Programa de Pós-Graduação em Geografia (PPGEO), ambos da Universidade Federal de Goiás (UFG).

Artigo recebido em: 05 de setembro de 2020.

Artigo aceito em: 02 de novembro de 2020.

Artigo publicado em: 07 de dezembro de 2020 